\title{
Effect of Processing on Synthesis and Dielectric Behavior of Bismuth Sodium Titanate Ceramics
}

\author{
Vijayeta Pal, ${ }^{1}$ R. K. Dwivedi, ${ }^{1}$ and O. P. Thakur ${ }^{2}$ \\ ${ }^{1}$ Department of Physics and Material Science \& Engineering, Jaypee Institute of Information Technology, Noida 201307, India \\ ${ }^{2}$ Electroceramics Group, Solid State Physics Laboratory, Defence Research and Development Organization (DRDO), Timarpur, \\ Delhi 110054, India
}

Correspondence should be addressed to Vijayeta Pal; vijayetapal@yahoo.in

Received 29 June 2012; Accepted 20 November 2012

Academic Editor: Baolin Wang

Copyright (C) 2013 Vijayeta Pal et al. This is an open access article distributed under the Creative Commons Attribution License, which permits unrestricted use, distribution, and reproduction in any medium, provided the original work is properly cited.

\begin{abstract}
An effort has been made to synthesize polycrystalline $\left(\mathrm{Bi}_{1-x} \mathrm{La}_{x}\right)_{0.5} \mathrm{Na}_{0.5} \mathrm{TiO}_{3}$ (abbreviated as $\mathrm{BLNT}$ ) system with compositions $x=0,0.02$, and 0.04 by novel semiwet technique. Preparation of A-site oxides of BLNT for composition $x=0$ was optimized using two precursor solutions such as ethylene glycol and citric acid. The XRD patterns revealed that the sample prepared by ethylene glycol precursor solution has single phase perovskite structure with a rhombohedral symmetry at RT as compared to the sample prepared by citric acid. Ethylene glycol precursor has been found to play a significant role in the crystallization, phase transitions, and electrical properties. The studies on structure, phase transitions, and dielectric properties for all the samples have been carried out over the temperature range from RT to $450^{\circ} \mathrm{C}$ at $100 \mathrm{kHz}$ frequency. It has been observed that two phase transitions (i) ferroelectric to antiferroelectric and (ii) antiferroelectric to paraelectric occur in all the samples. All samples exhibit a modified Curie-Weiss law above Tc. A linear fitting of the modified Curie-Weiss law to the experimental data shows diffuse-type transition. The dielectric as well as ferroelectric properties of BLNT ceramics have been found to be improved with the substitution of La elements.
\end{abstract}

\section{Introduction}

Lead oxide-based ceramics with perovskite structure have been the subject of attraction for high-performance sensors, actuators, transducers, and other applications, owing to their superior dielectric, piezoelectric, and electromechanical coupling coefficients. Applications are restricted to temperature range -50 to $150^{\circ} \mathrm{C}$ [1]. However, in recent years many fields have expressed the need for actuation and sensing which can be used at higher temperatures $\left(>400^{\circ} \mathrm{C}\right)$ such as automotive, aerospace, and related industrial applications. On the other hand, in most of the cases lead constitutes more than $60 \%$ of the composition of these piezoelectric devices. Lead, known to be highly toxic and volatile, is released to the atmosphere during sintering causing serious environmental and health problems. Another cause for concern is the disposal of these products at the end of the life cycle. Considering all these health concerns posed by lead, multinational governments like the European Union have enacted laws that ban the use of lead in the manufacture of many industrial products [2]. This has led to the replacement of lead $(\mathrm{Pb})$ in the field of piezoelectric ceramics. A lot of research has been carried out on lead-free piezoceramic products in the last fifty years but in the last few years, the momentum has tremendously increased, accounting for about $75 \%$ of all published works in this field. $\mathrm{Bi}_{0.5} \mathrm{Na}_{0.5} \mathrm{TiO}_{3^{-}}$(BNT-) and $\mathrm{K}_{0.5} \mathrm{Na}_{0.5} \mathrm{NbO}_{3^{-}}$(KNN-) based materials are two main material systems with perovskite structure, which have been studied to find the substitute of PZT for lead free piezoelectric applications. Pure BNT was discovered by Smolenskii et al. [3] and is a ferroelectric having $\mathrm{Bi}^{3+}$ and $\mathrm{Na}^{+}$complexes on the $\mathrm{A}$ site of $\mathrm{ABO}_{3}$-type perovskite structure with a rhombohedral symmetry. Because of a large remanent polarization $\left(P_{r}=\right.$ $38 \mu \mathrm{C} / \mathrm{cm}^{2}$ ) at room temperature, BNT ceramic is considered as one of the promising candidates for lead free piezoelectric ceramics [4]. However, the poling of pure BNT ceramic is 
very difficult due to its high coercive field $\left(E_{c}=73 \mathrm{kV} / \mathrm{cm}\right)$. So, the pure BNT ceramic usually exhibits weak piezoelectric properties. Therefore, a number of BNT-based ceramics were prepared to improve the electrical properties of this material by the convectional solid state method $[5,6]$. Recently, a lot of efforts have been made to prepare the material by various chemical methods, such as hydrothermal process [7], citrate method [8,9], sol-gel, autocombustion [10], and stearic acid gel route [11]. In the present work, A-site oxides of lead-free $\mathrm{Bi}_{0.5} \mathrm{Na}_{0.5} \mathrm{TiO}_{3}$ ceramics were optimized using two precursor solutions such as ethylene glycol and citric acid at low calcination temperature $\left(750^{\circ} \mathrm{C}\right)$ and further some La doped BNTs (BLNTs) have been developed using ethylene glycols precursors by a novel semiwet technique and structural, dielectric, and ferroelectric properties have been studied for both systems. To the best of our knowledge, BLNT system has been synthesized for the first time using semiwet technique. This technique has been applied to make other systems enhance its properties [12].

\section{Experimental Procedures}

A novel semiwet technique was used to prepare lead-free ceramic $\left(\mathrm{Bi}_{1-x} \mathrm{La}_{x}\right)_{0.5} \mathrm{Na}_{0.5} \mathrm{TiO}_{3}$ (BLNT) system. These compositions were prepared using analytical-grade metal oxides or nitrate powders of sigma Aldrich as raw materials such as $\mathrm{Bi}_{2} \mathrm{O}_{3}$ (99\%), $\mathrm{La}_{2} \mathrm{O}_{3}$ (99\%), $\mathrm{NaNO}_{3}$ (99\%), $\mathrm{TiO}_{2}(99.9 \%)$ citric acid, and ethylene glycol. In this method, A-site of BLNT with composition $x=0$ was prepared by using two different precursor solutions; the first one is citric acid, and; the second is ethylene glycol. In the first process, an appropriate amount of citric acid solution was added to the solution of nitrates of $\mathrm{A}$-site cations in a beaker $(\mathrm{C} / \mathrm{M} \sim 1: 1)$. Aqueous ammonia in the solution form was added drop by drop to adjust the $\mathrm{pH}$ value of the solution in the range of 6-8. The precursor solution was dehydrated by putting on heater with continuous stirring at $80^{\circ} \mathrm{C}$ for $3 \mathrm{hrs}$ to form a viscous gel which was placed in an oven at $150^{\circ} \mathrm{C}$ for overnight to combust the gel into ash powder. In the second process, stoichiometry amount of the solution of nitrates of A-site cation was dissolved with the ethylene glycol $(\mathrm{E} / \mathrm{M} \sim 1: 1)$ with continuous stirring for $30 \mathrm{~min}$ to get homogeneously mixed solution. The precursor solution was dehydrated by the same conditions, which is discussed in the first method to form a gel into ash powder. Both precursor solutions are expected to distribute the cations atomically homogeneously throughout the polymeric structure forming a stable polymeric complex, which was combusted at appropriate temperature $\left(T \sim 500^{\circ} \mathrm{C}\right)$ in the form of ash powder. The ash, highly fine, homogeneous, and highly reactive powder was mixed with appropriate amounts of $\mathrm{TiO}_{2}$ powder thoroughly in ethanol using mortal pestle for $2 \mathrm{hrs}$ followed by solid state route. These powders were dried and calcined at $750^{\circ} \mathrm{C}$ ( $2 \mathrm{hrs}$ ) for BNT-CA and BNT-EG and calcined at $850^{\circ} \mathrm{C}$ ( 2 hrs) for BLNT samples. The calcined powder was mixed thoroughly with a polyvinyl alcohol (PVA) binder solution and then pressed into the form of disk with $10 \mathrm{~mm}$ diameter. All samples are in pellet form, kept in alumina boat, and

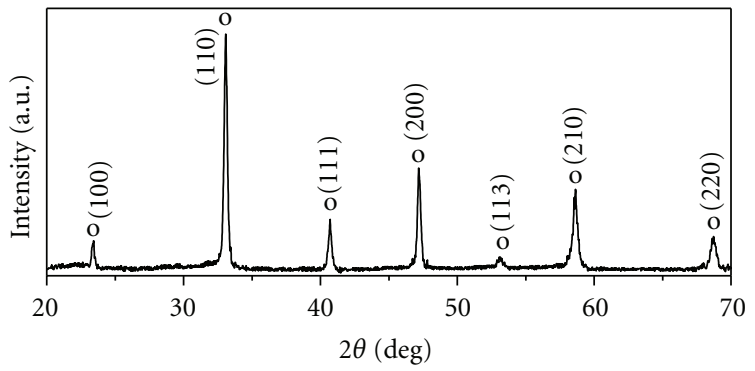

o Perovskite structure

(a)

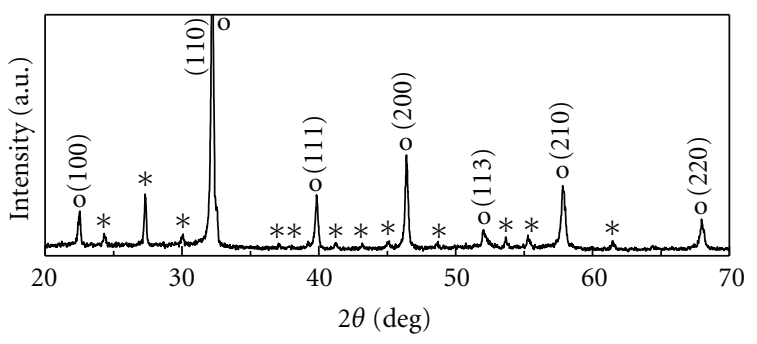

* $\mathrm{Bi}_{2} \mathrm{Ti}_{2} \mathrm{O}_{7}$

(b)

FIgURE 1: XRD patterns of (a) BNT-EG and (b) BNT-CA samples.

sintered at temperature $1150^{\circ} \mathrm{C}$ for 2 hours. Two pellets of each composition were electroded with silver paint on both the surfaces of the samples for the subsequent electrical measurements. The crystallite size of all the samples in BLNT system was calculated using Debye-Scherrer formula $(D=$ $\left.0.89 \lambda / \beta \cos \theta_{B}\right)$ where $D$ is the average crystallite size, $\lambda$ is the wavelength of $\mathrm{X}$-ray radiation, $\beta$ is the full width at half maximum (FWHM), and $\theta_{B}$ the diffraction angle. The corresponding values are reported in Table 1.

The crystalline structure of the sintered samples was examined using X-ray diffraction (XRD) analysis with $\mathrm{Cu}$ $\mathrm{K} \alpha$ radiation (DX-1000). The surface morphology of sintered ceramics was observed by scanning electron microscopy (SEM, model JEOL A 800). The dielectric constant $\varepsilon_{r}$ and dielectric loss $(\tan \delta)$ of the ceramic samples at $100 \mathrm{kHz}$ were measured as a function of temperature over the temperature range from room temperature to $450^{\circ} \mathrm{C}$ using an LCR meter (Hioki 3522). A conventional $P-E$ loop tracer (Marine India), which is based on Sawyer-Tower circuit, was used to measure the polarization-electrical field $(P-E)$ hysteresis loop at $50 \mathrm{~Hz}$.

\section{Results and Discussion}

In the present work, preparation of pure $\mathrm{Bi}_{0.5} \mathrm{Na}_{0.5} \mathrm{TiO}_{3}$ was optimized using two chemical precursors, citric acid and ethylene glycol. These samples are abbreviated as BNT-CA and BNT-EG (Figures 1(a) and 1(b)). It is observed from the XRD patterns that the sample prepared by ethylene glycol precursor solution has shown better phase formation, whereas BNT-CA has formed partially along with 
TABLE 1: Dielectric properties of all BLNT system, prepared using ethylene glycol precursor.

\begin{tabular}{|c|c|c|c|c|c|c|c|c|c|c|}
\hline Composition $(x)$ & $\begin{array}{l}\text { Lattice parameter } \\
a=b=c(\AA)\end{array}$ & $\begin{array}{l}\text { Volume } \\
\left(\mathrm{m}^{3}\right)\end{array}$ & $\varepsilon_{r}$ at $\mathrm{RT}$ & $\operatorname{Tan} \delta$ at $\mathrm{RT}$ & $\varepsilon_{r}$ at $T_{m}$ & $\operatorname{Tan} \delta$ at $T_{m}$ & $\begin{array}{l}T_{d} \\
{ }^{\circ} \mathrm{C}\end{array}$ & $\begin{array}{c}T_{m} \\
{ }^{\circ} \mathrm{C}\end{array}$ & $\gamma$ & $\begin{array}{l}D \\
(\mathrm{~nm})\end{array}$ \\
\hline $\mathrm{BNT}(x=0)$ & 3.868 & $5.78 * 10^{-29}$ & 705 & 0.040 & 3200 & 0.08 & 180 & 353 & 1.26 & 34.98 \\
\hline $\operatorname{BLNT}(x=0.02)$ & 3.931 & $6.07 * 10^{-29}$ & 1036 & 0.044 & 3630 & 0.03 & 200 & 355 & 1.49 & 39.33 \\
\hline BLNT $(x=0.04)$ & 3.922 & $6.03 * 10^{-29}$ & 3020 & 0.045 & 5630 & 0.05 & 210 & 380 & 1.80 & 34.81 \\
\hline
\end{tabular}

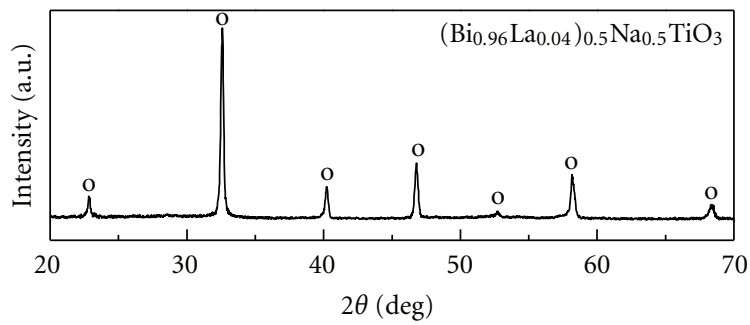

o Perovskite structure

(a)

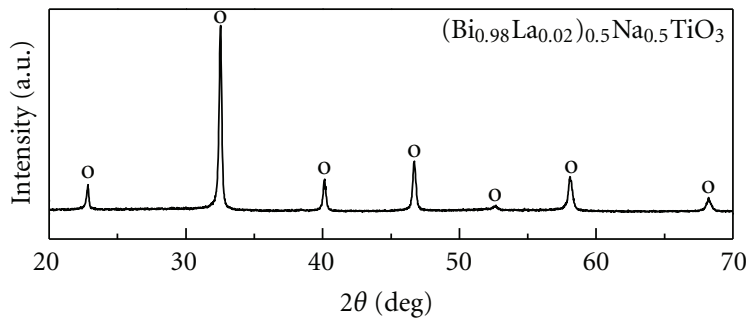

(b)

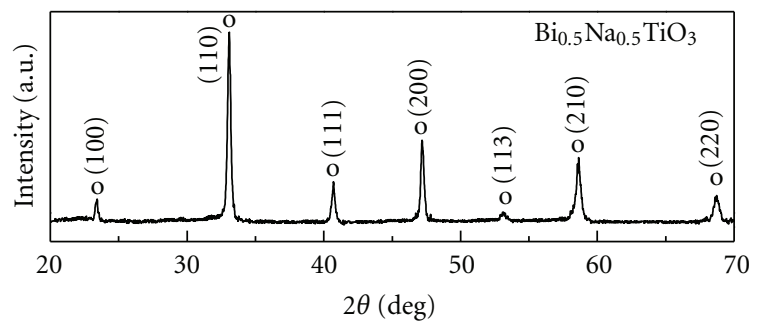

(c)

FIGURE 2: XRD patterns of BLNT system with compositions $x=$ $0,0.02$, and 0.04 .

the presence of other phase identified as $\mathrm{Bi}_{2} \mathrm{Ti}_{2} \mathrm{O}_{7}$ [13]. The experimental density observed in BNT-EG sample was $5.77 \mathrm{gm} / \mathrm{cm}^{2}$ which is $95 \%$ of theoretical density and the experimental density observed in BNT-CA sample was $5.56 \mathrm{gm} / \mathrm{cm}^{2}$ which is $91 \%$ of theoretical density. Therefore, a typical $\left(\mathrm{Bi}_{1-x} \mathrm{La}_{x}\right)_{0.5} \mathrm{Na}_{0.5} \mathrm{TiO}_{3}$ (BLNT) system with compositions $x=0.02$ and 0.04 was prepared by semiwet technique using ethylene glycol precursor, calcined at $850^{\circ} \mathrm{C}$. The $\mathrm{XRD}$ patterns of all the samples in BLNT system have shown single phase formation with a rhombohedral symmetry in Figure 2.

Pure BNT and BLNT powders have rhombohedral symmetry at room temperature. However, rhombohedral structure is hard to distinguish due to the overlapping of peaks that could be due to nearly cubic lattice parameter. Owing to small degree of rhombohedral distortion, diffraction lines were indexed on the basis of pseudocubic unit cell [14] and lattice parameters of all the BLNT samples, prepared by ethylene glycol, are calculated by using the Unit Cell program package [15]. There is a variation in the lattice parameters because of the different sizes of ionic radius of $\mathrm{La}^{3+}(1.03 \AA)$ which are close to $\mathrm{Bi}^{3+}$ ionic radius $(0.96 \AA)$ and $\mathrm{Na}^{+}(0.99 \AA)$. The values in the parentheses refer to the Shannon's effective ionic radius with the coordination number of six taken from [16].

The microstructure of the pure BNT ceramics, prepared by semiwet using ethylene glycol and citric acid, sintered at $1150^{\circ} \mathrm{C}$ is shown in Figure 3. Ethylene glycol precursor plays a significant role in the grain growth and densification. The microstructure of pure BNT-EG ceramics is denser, homogeneous, and uniform grains with grain size of $2.12 \mu \mathrm{m}$ as compared to BNT-CA with grain size of $1.19 \mu \mathrm{m}$.

The dielectric measurements of electroded samples of BNT-EG, BNT-CA, and BLNT samples were carried at $100 \mathrm{kHz}$ frequency over temperature range from room temperature to $450^{\circ} \mathrm{C}$ and are shown in Figures 4(a), 4(b), 4(c), and $4(\mathrm{~d})$, respectively.

Two dielectric anomalies in all the samples are shown at temperatures $T_{1}$ and $T_{2}$, termed as " $T_{d}$ " and " $T_{m}$ " respectively, which corresponds to dielectric transitions from ferroelectric (FE) to anti-ferroelectric (AFE) and anti-ferroelectric (AFE) to paraelectric (PE), respectively. The corresponding peaks also appear in $\tan \delta$ versus $T$ plots. However, the low value of dielectric constant of the sample, prepared using citric acid (BNT-CA), may be due to formation of other phases of $\mathrm{Bi}_{2} \mathrm{Ti}_{2} \mathrm{O}_{7}$, which hampers the one dielectric anomaly and relative value of dielectric constant in this sample. It has been observed that the $T_{d}$ and $T_{m}$ shift to higher temperature with increasing the concentration of $\mathrm{La}^{3+}$. The partial replacement of A-site cation, with larger ionic radius cations and larger amount, decreases the relative displacement of B-site cation with respect to the oxygen octahedral cage and hence the increase in transition temperature is observed with substitution of $\mathrm{La}$ at $\mathrm{A}$-site. It is obvious that $\mathrm{La}^{3+}(1.03 \AA)$ can occupy the A-site of $\mathrm{Bi}^{3+}(0.96 \AA)$ or $\mathrm{Na}^{+}$ $(0.99 \AA)$. When $\mathrm{La}^{3+}$ occupies A-site of $\mathrm{Na}^{+}$, it will lead to charge imbalance, which creates defects on A-site. In general, A-site $\left(\mathrm{Bi}^{3+}\right.$ and $\left.\mathrm{Na}^{+}\right)$substitution by $\mathrm{La}^{3+}$ in BNT ceramics can be formulated in the following way:

$$
\begin{gathered}
\mathrm{La}_{2} \mathrm{O}_{3}+\mathrm{BNT} \longrightarrow 2 \mathrm{La}_{\mathrm{Bi}}+3 \mathrm{O}_{\mathrm{o}} \\
\mathrm{La}_{2} \mathrm{O}_{3}+\mathrm{BNT} \longrightarrow 2 \mathrm{La}_{\mathrm{Na}}+4 V_{\mathrm{Na}}^{\prime}+3 \mathrm{O}_{\mathrm{o}}
\end{gathered}
$$




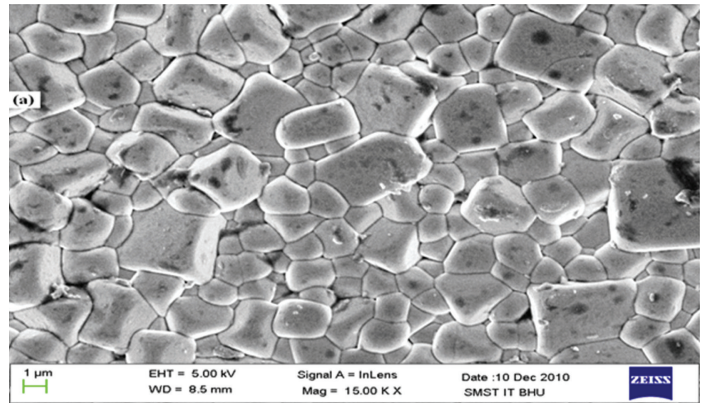

(a)

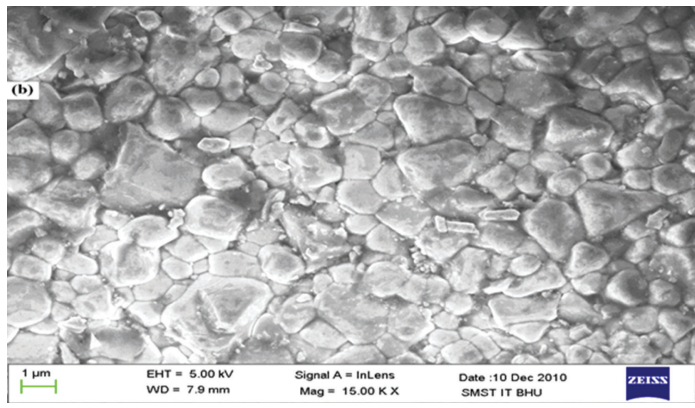

(b)

FIGURE 3: Microphotographs patterns of (a) BNT-EG and (b) BNT-CA samples.

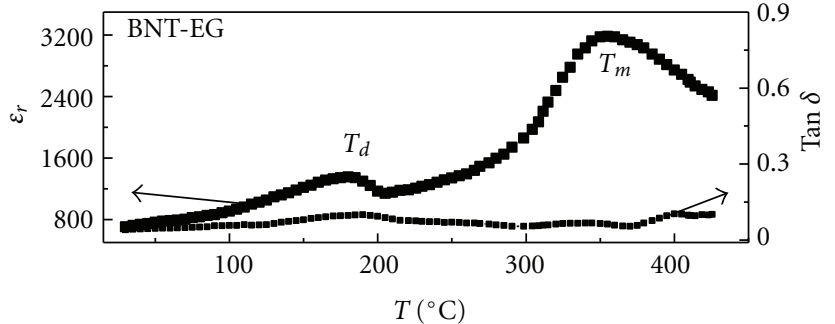

$--100 \mathrm{kHz}$

(a)

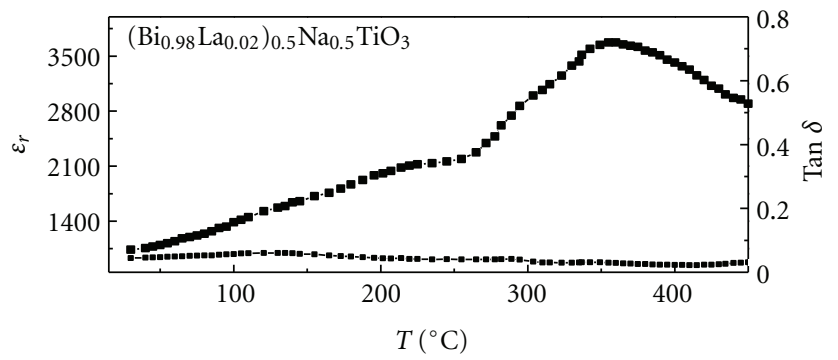

(c)

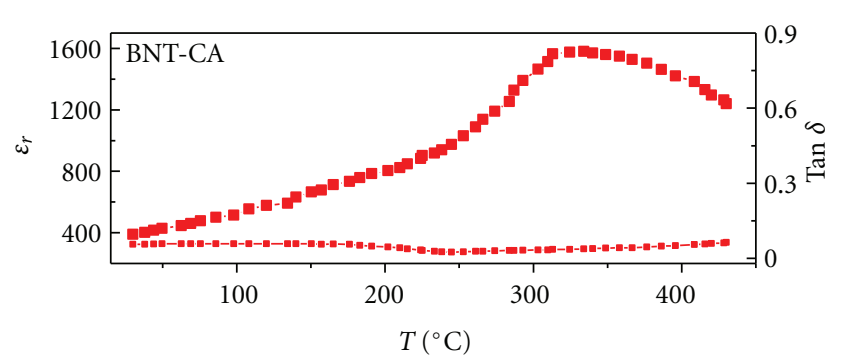

(b)

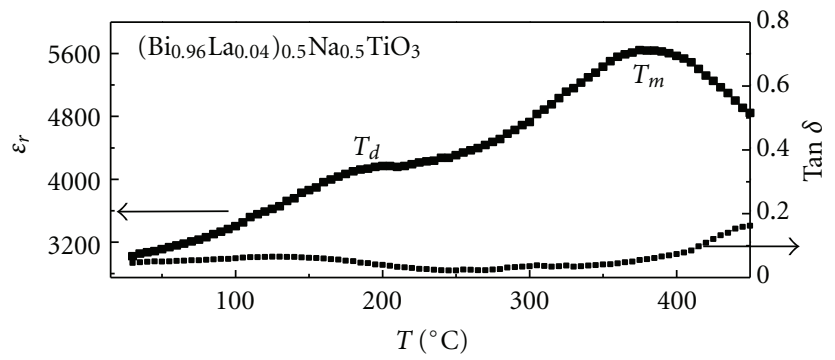

(d)

FIgURE 4: Variations of $\varepsilon_{r}$ and $\tan \delta$ with temperature for samples (a) BNT-EG, (b) BNT-CA, (c) BLNT with $x=0.02$, and (d) $x=0.04$.

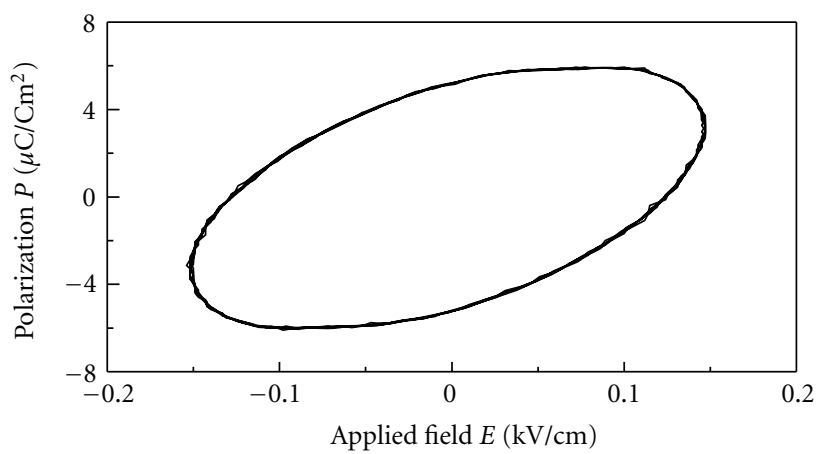

$E_{c}=0.12$

$P_{r}=5.3$

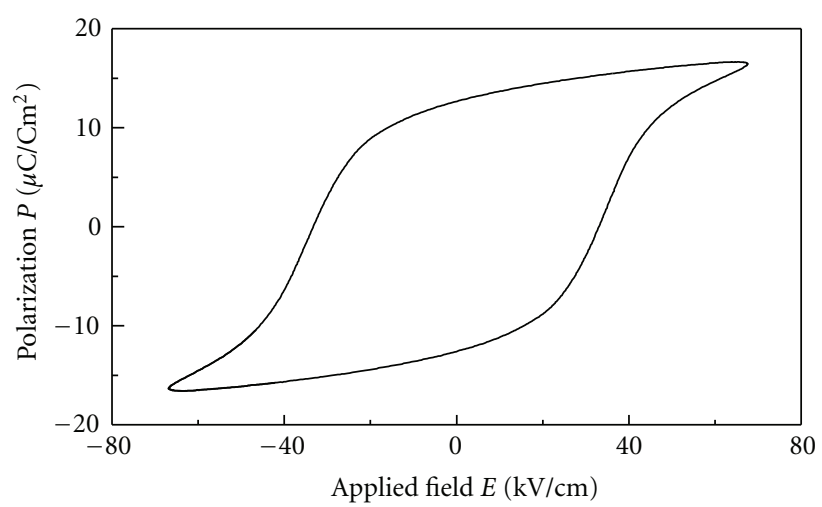

$P_{r}=13.16$

$E_{c}=25.02$

(a)

(b)

Figure 5: The P-E hysteresis loops at RT (50 Hz) (a) for BNT-CA and (b) BNT-EG. 
TABLE 2: Ferroelectric properties of all saturated BLNT system, prepared using ethylene glycol precursor.

\begin{tabular}{lccc}
\hline Composition $(x)$ & $P_{r}\left(\mu \mathrm{C} / \mathrm{cm}^{2}\right)$ & $P_{\max }\left(\mu \mathrm{C} / \mathrm{cm}^{2}\right)$ & $E_{c}(\mathrm{kV} / \mathrm{cm})$ \\
\hline $\operatorname{BNT}-E G(x=0)$ & 13.16 & 16.90 & 25.02 \\
$\operatorname{BLNT}(x=0.02)$ & 13.33 & 17.86 & 24.96 \\
$\operatorname{BLNT}(x=0.04)$ & 17.70 & 20.60 & 36.73 \\
\hline
\end{tabular}

When $\mathrm{La}^{3+}$ occupies Bi-site, as shown in (1), the substitution of $\mathrm{Bi}^{3+}$ by $\mathrm{La}^{3+}$ may cause the slack of BLNT lattice. The lattice deformation can make the ferroelectric domains reorientation more easily. It leads to the enhancement of dielectric as well as ferroelectric properties. Additionally, $\mathrm{La}^{3+}$ can also occupy the A-site of $\mathrm{Na}^{+}$, as shown in (2). In this case, the valence of $\mathrm{La}^{3+}$ ion is higher than that of $\mathrm{Na}^{+}$ion. To maintain overall electrical neutrality, $\mathrm{La}^{3+}$ acts as a donor leading to some Na-site vacancies $\left[V_{\mathrm{Na}}^{\prime}\right]$, which can relax the strain caused by reorientation of domains. Therefore, the movement of the domains becomes easier and thus the electrical properties of the BLNT ceramics are improved significantly. Thus, the substitution of $\mathrm{La}^{3+}$ in BNT system has significantly influenced the phase transition and dielectric behavior (Figures $4(\mathrm{c})$ and $4(\mathrm{~d})$ ). The highest value of $\varepsilon_{r}(\sim 3020)$ and lowest value of $\operatorname{Tan} \delta(\sim 0.045)$ are obtained with the composition $x=0.04$ in the BLNT system at room temperature. The physical and dielectric properties of all the BLNT samples are tabulated at RT $(100 \mathrm{kHz})$ in Table 1.

It shows the typical character of a ferroelectric behavior around transition temperature because of diffused phase transition. Dielectric constant exhibits strong frequency dependence above $T_{d}$ and the maximum value of $\varepsilon_{r}$ decreases as frequency increases in the BNT-EG samples suggesting that the ceramic is relaxor ferroelectric. The diffuseness in the phase transition can be described by $1 / \varepsilon_{r}-1 / \varepsilon_{r \max }=$ $C^{-\gamma}\left(T-T_{m}\right)^{\gamma}$ in relaxor ferroelectrics [17], where $\varepsilon_{r \max }$ is the maximum value of dielectric constant at $T_{m}, \gamma$ is the degree of diffuseness, and $C$ is the curie-like coefficient. $\gamma$ can have a value ranging from 1 for normal ferroelectric to 2 for an ideal relaxor ferroelectric. This sample exhibits a linear relationship. The value of the exponent " $\gamma$ " was determined by least-squared fitting experimental data to the equation which is in the range of 1.50 to 1.80 . This confirms the diffuse phase transition in BLNT-EG system. The polarizationelectrical field $(P-E)$ hysteresis loop is shown in Figures 5(a) and 5(b). It has been found that the P-E loop of BNT using citric acid is round shaped, not well developed (saturated), Figure 4(a). BNT-CA sample gets breakdown with increasing electric field. This may be due to (I) large leakage current and (II) due to insufficient annealing process. $P$-E loop for BNT sample prepared using ethylene glycol is well developed or saturated, Figure 5(b).

This may be attributed to smaller grain size and relatively better density of the samples and confirm that all the samples are ferroelectric in nature.

The ferroelectric properties of all the BLNT system are tabulated at RT $(50 \mathrm{~Hz})$ in Table 2.

\section{Conclusion}

In summary, ethylene glycol prepared samples have revealed better crystallization of pure phase for BNT-EG sample. XRD patterns have revealed that the sample BNT-EG has single phase perovskite structure with a rhombohedral symmetry at RT. The structural, phase transition, and electrical properties of all the samples were investigated. The Bismuth sodium titanate, prepared by ethylene glycol precursor, has not only shown excellent dielectric but also ferroelectric behavior. The BNT sample has high value of dielectric constant $\left(\varepsilon_{r}=705\right)$, dielectric loss $(\operatorname{Tan} \delta=0.04)$, remnant polarization $\left(P_{r}=\right.$ $\left.13.16 \mu \mathrm{C} / \mathrm{Cm}^{2}\right)$, and Coercive field $\left(E_{c}=25.06 \mathrm{kV} / \mathrm{Cm}\right)$ at room temperature. The relatively highest value of dielectric constant for BLNT with composition $x=0.04$ may be attributed to the La doping. Composition with La substitution of $x=0.04$ has shown the highest value of dielectric (3020) constant and low loss (0.045) as well as the highest value of remanent polarization $\left(P_{r}=17.70 \mu \mathrm{C} / \mathrm{Cm}^{2}\right)$. The transition temperature $\mathrm{Tm}$ is also maximum $\left(385^{\circ} \mathrm{C}\right)$ for this composition which reveals that the material can be useful for high-temperature device applications.

\section{Acknowledgment}

One of the authors Ms. V. Pal is thankful to JIIT for providing teaching assistance ship and other research facilities to carry out her research work at JIIT, Noida (India).

\section{References}

[1] B. Jaffe, W. R. Cook Jr., and H. Jaffe, Piezoelectric Ceramics, vol. 3, Academic Press, London, UK, 1971.

[2] M. Pecht, Y. Fukuda, and S. Rajagopal, "The impact of leadfree legislation exemptions on the electronics industry," IEEE Transactions on Electronics Packaging Manufacturing, vol. 27, no. 4, pp. 221-232, 2004.

[3] G. A. Smolenskii, V. A. Isupov, A. I. Agranovskaya, and N. N. Krainik, "New ferroelectrics of complex composition," Soviet Physics, Solid State, vol. 2, pp. 2651-2654, 1961.

[4] T. Takenaka, K. I. Maruyama, and K. Sakata, " $\left(\mathrm{Bi}_{1 / 2} \mathrm{Na}_{1 / 2}\right) \mathrm{TiO}_{3}-\mathrm{BaTiO}_{3}$ system for lead-free piezoelectric ceramics," Japanese Journal of Applied Physics, Part 1, vol. 30, no. 9, pp. 2236-2239, 1991.

[5] A. Sasaki, T. Chiba, Y. Mamiya, and E. Otsuki, "Dielectric and piezoelectric properties of $\left(\mathrm{Bi}_{0.5} \mathrm{Na}_{0.5}\right) \mathrm{TiO}_{3}-\left(\mathrm{Bi}_{0.5} \mathrm{~K}_{0.5}\right) \mathrm{TiO}_{3}$ systems," Japanese Journal of Applied Physics, Part 1, vol. 38, no. 9, pp. 5564-5567, 1999.

[6] B. J. Chu, D. R. Chen, G. R. Li, and Q. R. Yin, "Electrical properties of $\mathrm{Na}_{1 / 2} \mathrm{Bi}_{1 / 2} \mathrm{TiO}_{3}-\mathrm{BaTiO}_{3}$ ceramics," Journal of the European Ceramic Society, vol. 22, no. 13, pp. 2115-2121, 2002.

[7] P. Pookmanee, G. Rujijanagul, S. Ananta, R. B. Heimann, and S. Phanichphant, "Effect of sintering temperature on microstructure of hydrothermally prepared bismuth sodium titanate ceramics," Journal of the European Ceramic Society, vol. 24, no. 2, pp. 517-520, 2004.

[8] Q. Xu, X. L. Chen, W. Chen, B. H. Kim, S. L. Xu, and M. Chen, "Structure and electrical properties of $\left(\mathrm{Na}_{0.5} \mathrm{Bi}_{0.5}\right)_{1-\mathrm{x}} \mathrm{Ba}_{x} \mathrm{TiO}_{3}$ ceramics made by a citrate method," Journal of Electroceramics, vol. 21, no. 1-4, pp. 617-620, 2008. 
[9] D. L. West and D. A. Payne, "Preparation of $0.95 \mathrm{Bi}_{1 / 2} \mathrm{Na}_{1 / 2} \mathrm{TiO}_{3} \cdot 0.05 \mathrm{BaTiO}_{3}$ ceramics by an aqueous citrate-gel route," Journal of the American Ceramic Society, vol. 86, no. 1, pp. 192-194, 2003.

[10] J. G. Hou, Y. F. Qu, W. B. Ma, and D. Shan, "Synthesis and piezoelectric properties of $\left(\mathrm{Na}_{0.5} \mathrm{Bi}_{0.5}\right)_{0.94} \mathrm{Ba}_{0.06} \mathrm{TiO}_{3}$ ceramics prepared by sol-gel auto-combustion method," Journal of Materials Science, vol. 42, no. 16, pp. 6787-6791, 2007.

[11] J. Hao, X. Wang, R. Chen, and L. Li, "Synthesis of $\left(\mathrm{Bi}_{0.5} \mathrm{Na}_{0.5}\right) \mathrm{TiO}_{3}$ nanocrystalline powders by stearic acid gel method," Materials Chemistry and Physics, vol. 90, no. 2-3, pp. 282-285, 2005.

[12] A. P. Singh, S. K. Mishra, D. Pandey, C. D. Prasad, and R. Lal, "Low-temperature synthesis of chemically homogeneous lead zirconate titanate (PZT) powders by a semi-wet method," Journal of Materials Science, vol. 28, no. 18, pp. 5050-5055, 1993.

[13] K. Kitagawa, T. Toyoda, K. Kitagawa, and T. Yamamoto, " $\left(\mathrm{Bi}_{1 / 2} \mathrm{Na}_{1 / 2}\right) \mathrm{TiO}_{3}$ additive effect for improved piezoelectric and mechanical properties in PZT ceramics," Journal of Materials Science, vol. 38, no. 10, pp. 2241-2245, 2003.

[14] E. Fukuchi, T. Kimura, T. Tani, T. Takeuch, and Y. Saito, "Effect of potassium concentration on the grain orientation in bismuth sodium potassium titanate," Journal of the American Ceramic Society, vol. 85, no. 6, pp. 1461-1466, 2002.

[15] N. Chaiyo, A. Ruangphanit, R. Muanghlua, S. Niemcharoen, B. Boonchom, and N. Vittayakorn, "Synthesis of potassium niobate (KNbO3) nano-powder by a modified solid-state reaction," Journal of Materials Science, vol. 46, no. 6, pp. 1585-1590, 2011.

[16] R. D. Shannon, "Revised effective ionic radii and systematic studies of interatomic distances in halides and chalcogenides," Acta Crystallographica, vol. 32, pp. 751-767, 1976.

[17] K. Uchino and S. Nomura, "Critical exponents of the dielectric constants in diffused-phase-transition crystals," Ferroelectrics Letters Section, vol. 44, no. 3, pp. 55-61, 1982. 

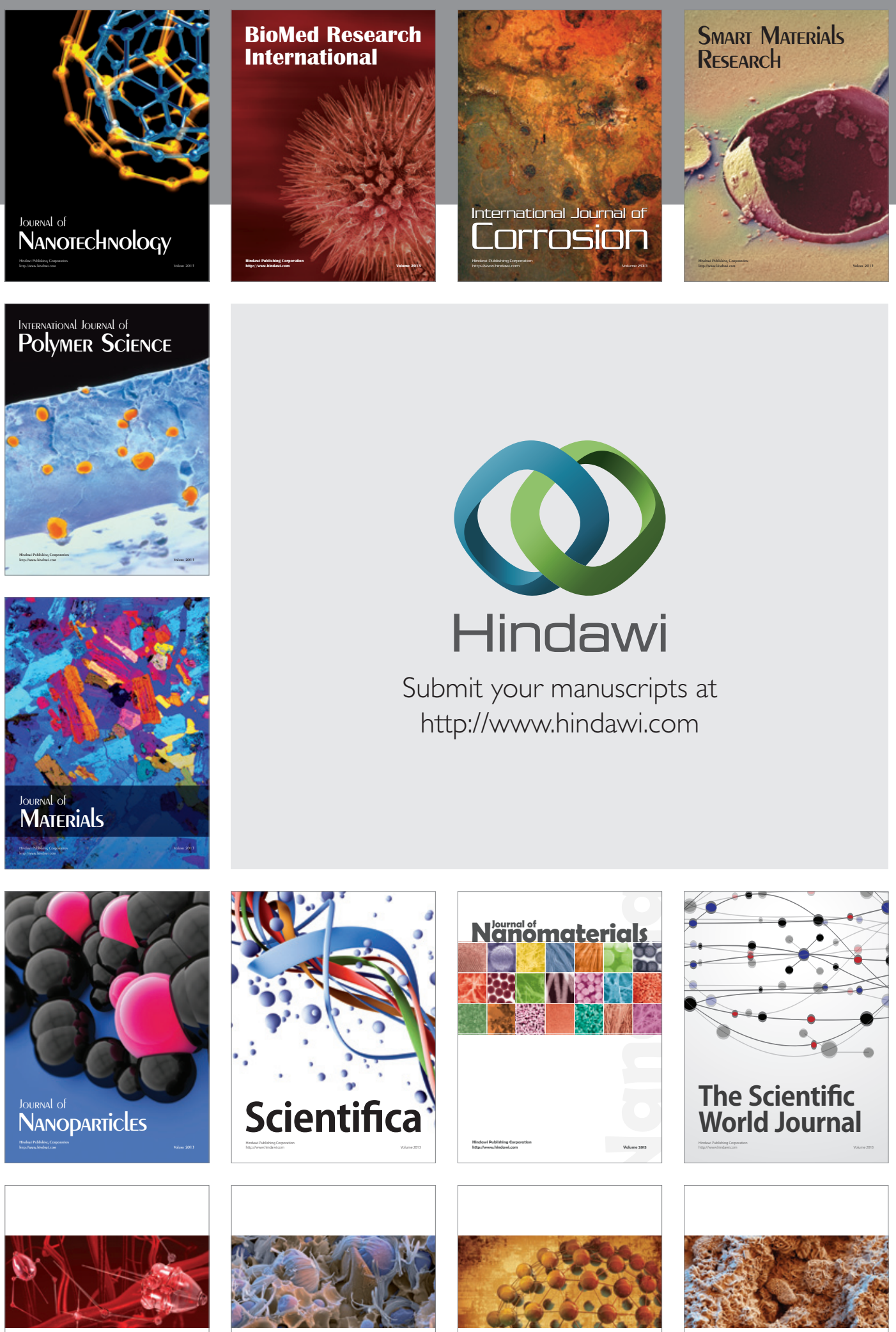

ISRN

Nanotechnology
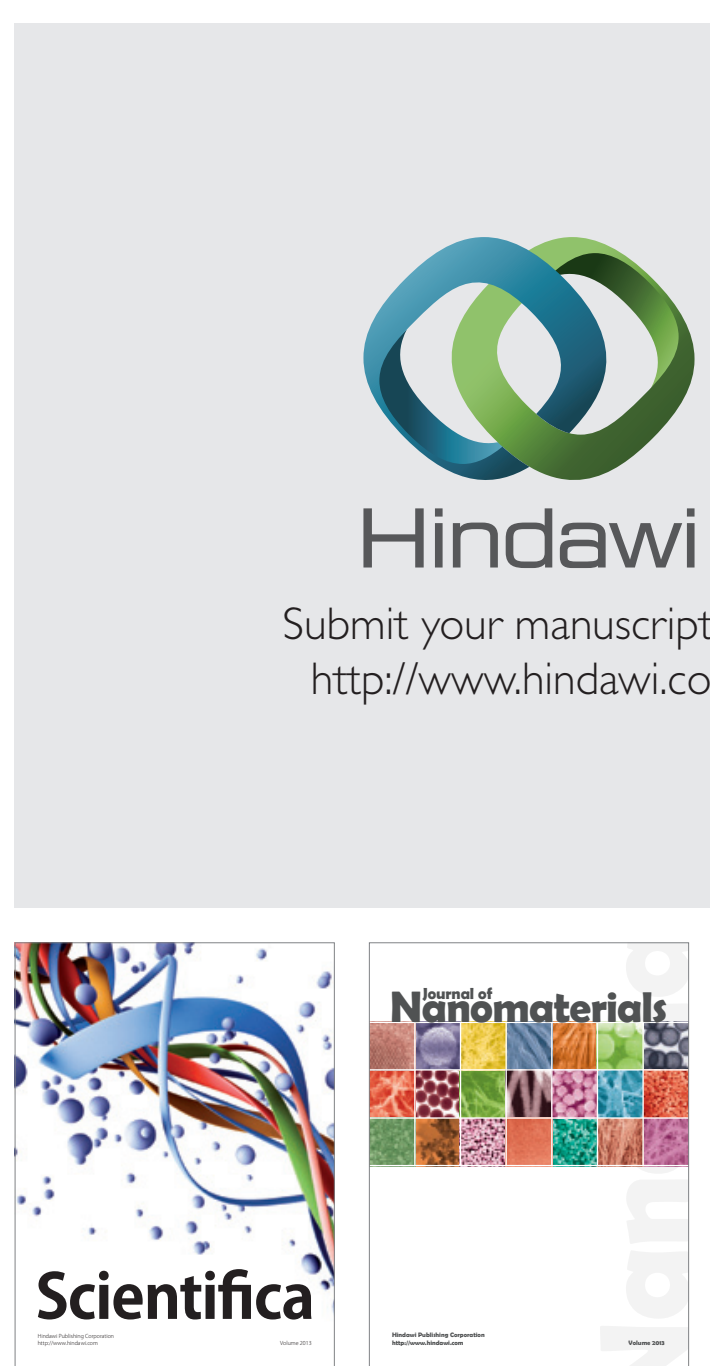

Submit your manuscripts at http://www.hindawi.com
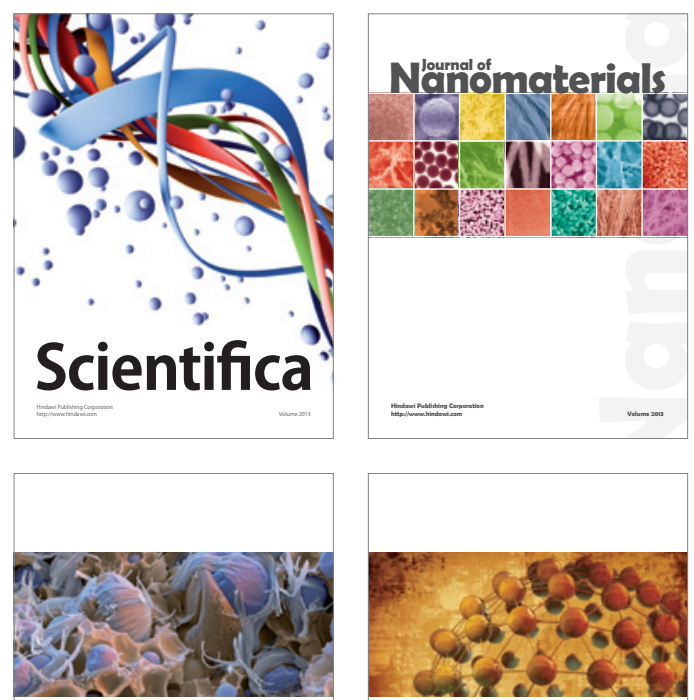

ISRN

Polymer Science

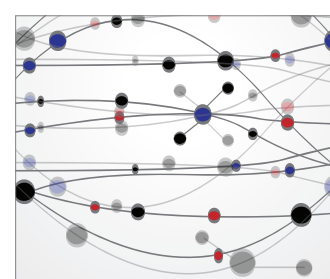

The Scientific World Journal

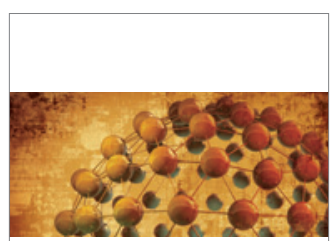

ISRN

Materials Science

\section{World Jounal}

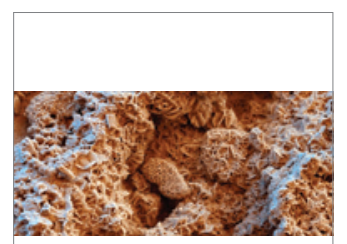

ISRN

Corrosion
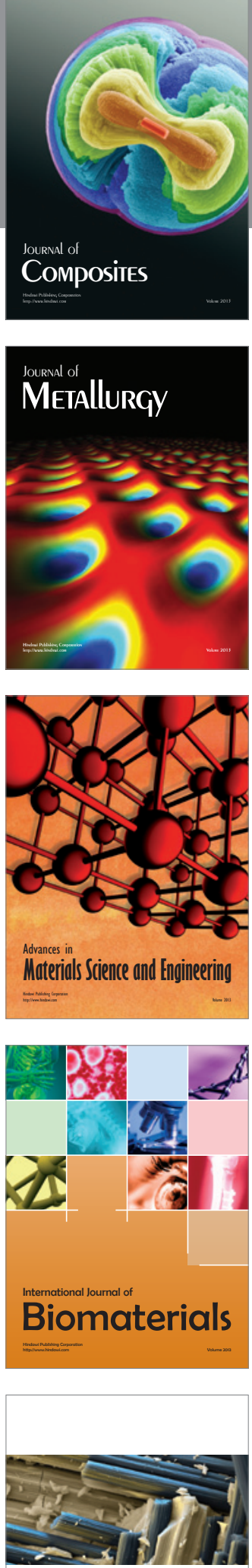

ISRN

Ceramics 